\title{
Repertoires of Autophagy in the Pathogenesis of Ocular Diseases
}

\author{
Yu-jie Lia,b Qin Jiang ${ }^{a, b, c}$ Guo-fan Cao ${ }^{a, b}$ Jin Yao ${ }^{a, b}$ Biao Yana,b,c \\ ${ }^{a}$ Eye Hospital, Nanjing Medical University, ${ }^{b}$ The Fourth School of Clinical Medicine, Nanjing Medical \\ University, Institute of Integrated Medicine, Nanjing Medical University, Nanjing, China
}

\section{Key Words}

Autophagy $\cdot$ Age-related macular degeneration $•$ Glaucoma $\cdot$ Cataract $•$ Diabetic retinopathy

- Photoreceptor degeneration

\begin{abstract}
Autophagy is an important intracellular degradative process that delivers cytoplasmic proteins to lysosome for degradation. Dysfunction of autophagy is implicated in several human diseases, such as neurodegenerative diseases, infectious diseases, and cancers. Autophagyrelated proteins are constitutively expressed in the eye. Increasing studies have revealed that abnormal autophagy is an important pathological feature of several ocular diseases. Pharmacological manipulation of autophagy may provide an alternative therapeutic target for some ocular diseases. In this manuscript, we reviewed the relevant progress about the role of autophagy in the pathogenesis of ocular diseases.

Copyright (C) 2015 S. Karger AG, Basel
\end{abstract}

\section{Introduction}

Cellular homeostasis requires a constant balance between biosynthetic and catabolic processes. Eukaryotic cells possess two major mechanisms for large-scale degradation, including proteasomeand autophagy [1].Autophagy is an evolutionarily conserved, genetically controlled cell pathway. Under normal physiological condition, autophagy regulates cellular homeostasis by eliminating damaged proteins/organelles for cellular component quality $[2,3]$. Under adverse condition, autophagy serves as an adaptive mechanism to protect Y.-j. Li and Q. Jiang contributed equally to this paper.

Biao Yan
Jin Yao $\quad \begin{aligned} & \text { Eye Hospital, Nanjing Medical University, 138\# Han-zhong Road, } \\ & \text { Nanjing, 210029 (China) } \\ & \text { Tel. +86-25-86677677, Fax+86-25-86677677, E-Mail yanbiao1982@hotmail.com, }\end{aligned}$


organisms against various disorders, such as cancer, aging, neurodegeneration, and cardiovascular disease [2, 4].

Aging and oxidative stress are recognized as the key pathological features in many ocular diseases. They lead to an increased amount of intracellular organelles and defective autophagic flux. Autophagy plays an important role in cellular homeostasis through removing abnormal organelles and proteins $[5,6]$. Autophagy-related proteins are strongly expressed in all retinal cells from those comprising the cornea in the front of the eye to the retinal pigment epithelium (RPE). Defective autophagy is tightly associated with the occurrence of ocular diseases. Thus, pharmacological manipulation of autophagy may offer an alternative therapeutic target [7]. In this review, we summarized the progress on the role of autophagy in ocular diseases, and the ongoing efforts for autophagy modulation for treating ocular diseases.

\section{Introduction of autophagy process}

Autophagy is a lysosomal process used by eukaryotes for degrading and recycling cellular constituents, such as long-lived proteins and entire organelles. There are three major forms of autophagy, including microautophagy, chaperone-mediated autophagy (CMA), and macroautophagy. Microautophagy and CMA directly involve the lysosome, which either engulfs a small part of cytosol or receives chaperone-associated cargoes, respectively [8]. Macroautophagy is a vacuolar degradative pathway terminating in the lysosomal compartment after forming autophagosome that engulfs macromolecules and organelles (Fig. 1) [9].

Macroautophagy plays important roles in survival, development and tissue homeostasis [10]. CMA is activated by physiological stresses such as prolonged starvation, which is shown as the only autophagic pathway that allows selective degradation of soluble proteins in lysosomes [11]. The maintenance of organelle size, membrane homeostasis, and cell survival under nitrogen restriction are the main functions of microautophagy. Microautophagy is also coordinated with and complements macroautophagy, CMA, and other self-eating pathways [12].

Macroautophagy cascade is a highly complex process, dividing into several discrete steps, including signaling induction; cargo selection and packaging; nucleation of vesicle formation; docking and fusion of the completed vesicle with the lysosome/vacuole; and breakdown of the intralumenal vesicle and its cargo and recycling of the macromolecular constituents (Fig. 2) [13, 14]. Microautophagy involves the direct engulfment of cytoplasmic cargo at the boundary membrane by autophagic tubes, which mediates both invagination and vesicle scission into the lumen. During CMA, the substrate proteins are targeted to lysosomal membrane by the recognition of a targeting motif (a KFERQ-like motif) by chaperone complex, hsc70 and its cochaperones. Once at the lysosomal membrane, the protein interacts with lysosomal associated membrane protein type $2 \mathrm{~A}$ (LAMP-2A), and is translocated across the membrane into the lysosomal lumen.

\section{Signaling pathway involved in autophagy regulation}

Currently, several signaling pathways have been implicated in autophagy regulation, such as mammalian target of rapamycin (mTOR), AMP-activated protein kinase (AMPK), NRF2/KEAP1, and ER stress signaling (Fig. 3). mTOR signaling can be activated by growth factors, and inhibited by AMPK and p53. Inhibition of mTOR stimulates autophagy, while enhanced mTOR activity impairs autophagy. Activated mTOR can phosphorylate ULK1/2, thereby inhibiting the downstream autophagy cascade. In contrast, AMPK suppresses mTORC1 signaling, and stimulates autophagy through TSC1/2 phosphorylation [15-17]. NRF2/KEAP1 is the major signaling responsible for cell defense against oxidative stress [18, 


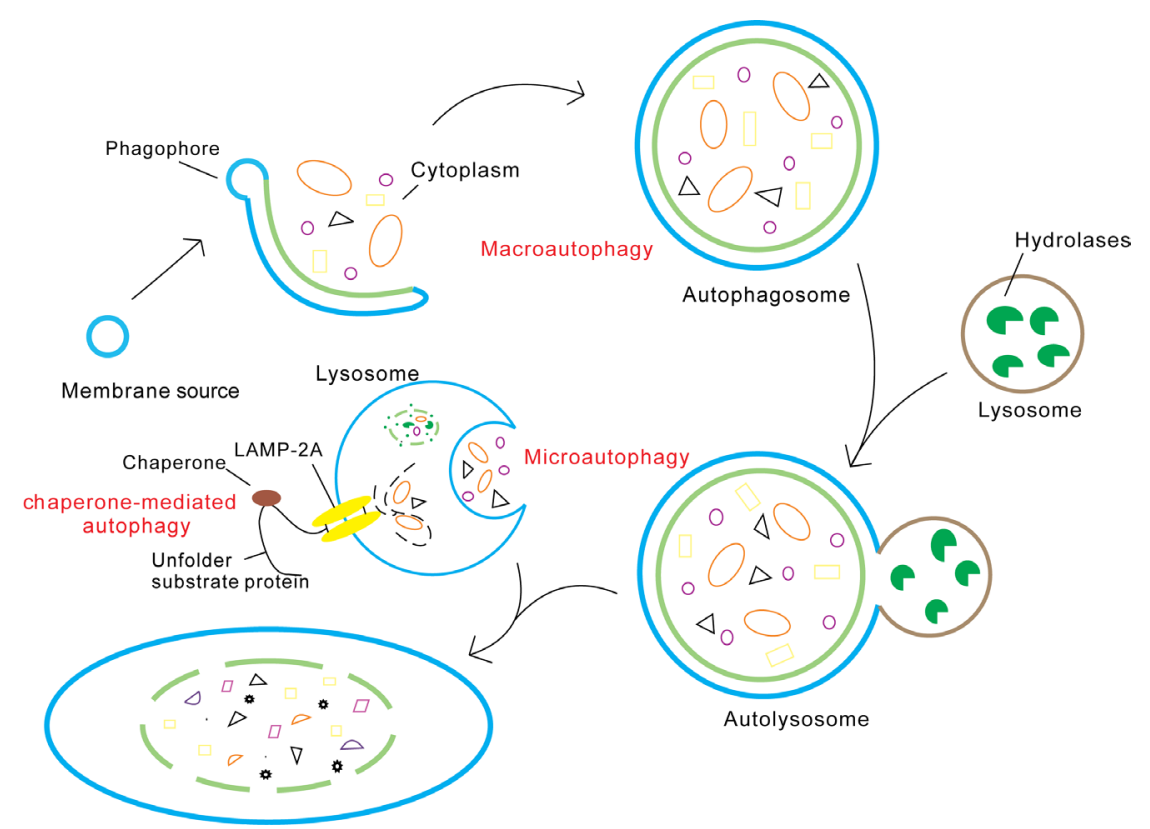

Fig. 1. Schematic model of different types of autophagy. During macroautophagy, the cargoes are sequestered within a unique double-membrane cytosolic vesicle, an autophagosome. Sequestration can be either nonspecific, involving the engulfment of bulk cytoplasm, or selective, targeting specific cargoes such as organelles or invasive microbes. Microautophagy is cytosolic components sequestration by lysosomes through invaginations in their limiting membrane. During CMA, the substrate proteins are targeted to the lysosomal membrane by a chaperone complex, hsc70 and its cochaperones. Once at the lysosomal membrane, the protein interacts with lysosomal associated membrane protein type 2A (LAMP-2A), translocated across the membrane into the lysosomal lumen assisted by chaperone.

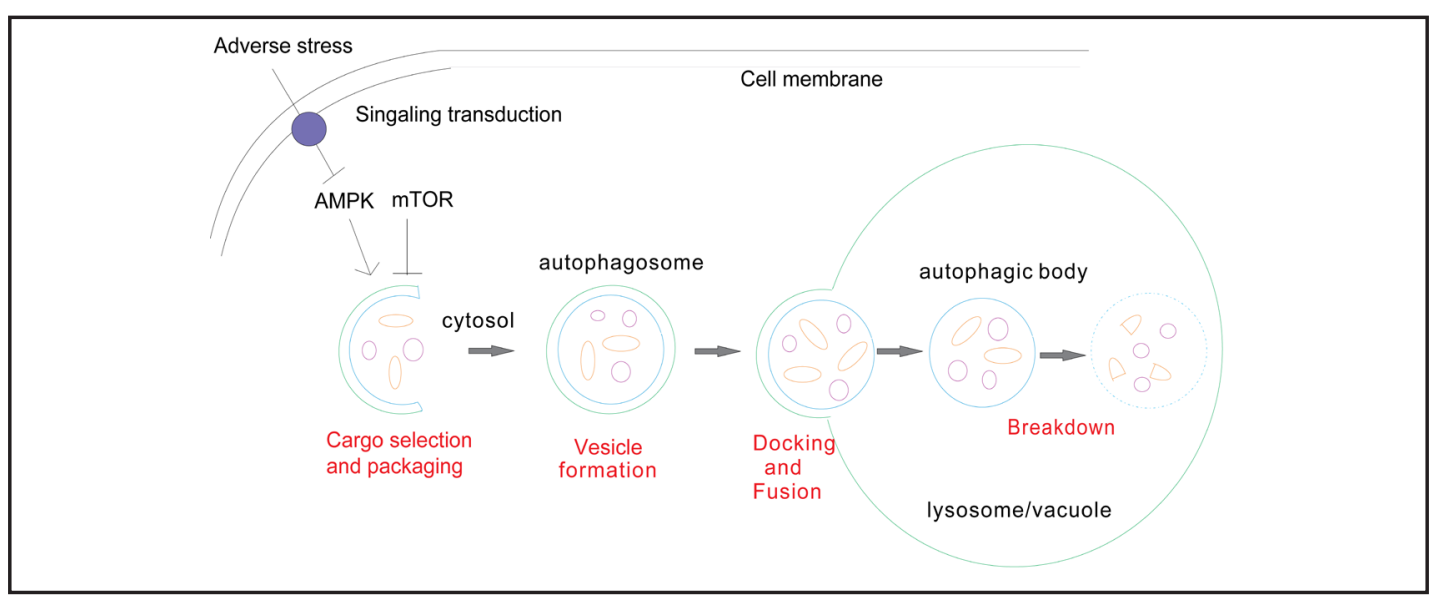

Fig. 2. Schematic depiction of autophagy pathway and its core molecular machinery. External stress leads to the inhibition of mTOR kinase, which in turn leads to autophagy activation. Membrane forms an unknown source which can nonspecifically sequester cytoplasm. The following double membrane autophagosome targets to and fuses with the lysosome. The fusion allows the release of the single-membrane autophagic body, which is degraded in the lumen allowing the recycling of cytoplamic constituents.

19]. It enables cell adaptation to oxidative stress caused by various stimuli, such as chemical oxidative, electrophilic agents, or UV radiation. Autophagy-deficient mice show aberrant p62 accumulation. p62 accumulation could disrupt NRF2/KEAP1 association and provoke 
Fig. 3. Signaling pathways involved in autophagy. Autophagy is regulated by a series of signaling cascades, including MTOR, NRF2/ KEAP1, ER stress, and AMPK signaling pathway.

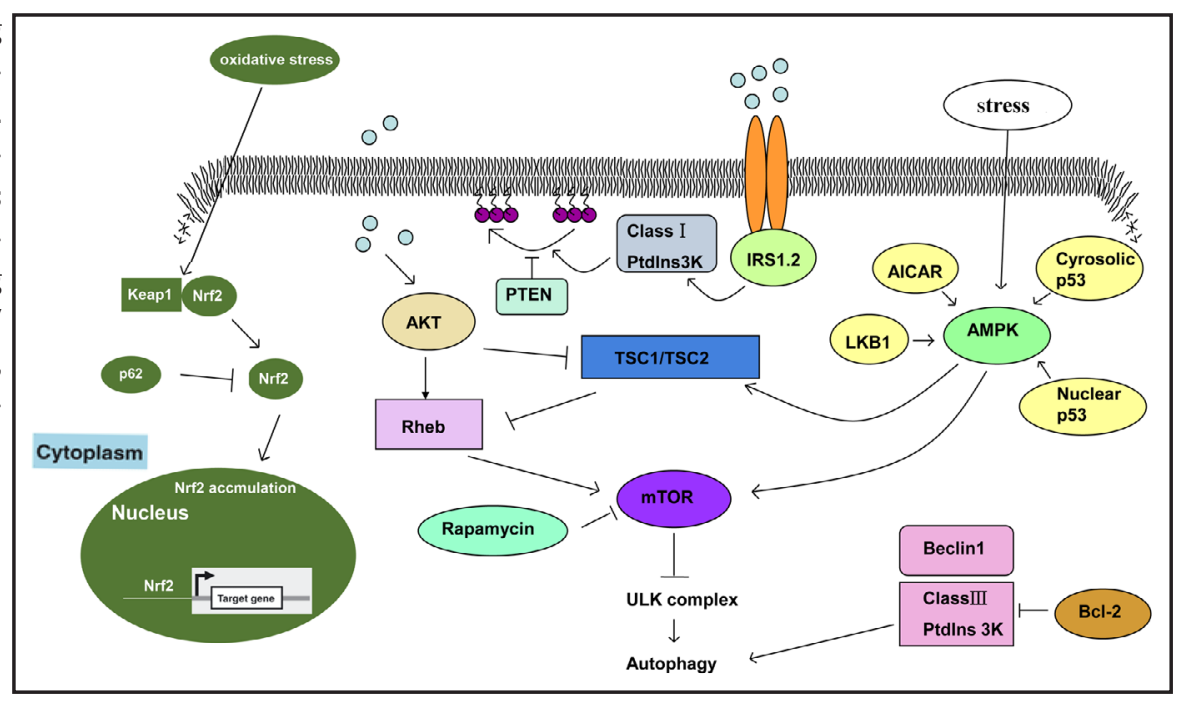

NRF2 stabilization and accumulation [20, 21]. In addition, p62 accumulation sequesters KEAP1 into aggregates, inhibiting KEAP1-mediated NRF2 ubiquitination [22]. ER stress can stimulate autophagy through PERK-eIF2 $\alpha$ pathway, IRE1-JNK1 pathway and $\mathrm{Ca}^{2+}$ release. Activation of eIF2 $\alpha$ by PERK contributes to the transcription of some autophagy genes [23].

\section{Physiological role of autophagy}

Autophagy is known as an adaptive process to defend against various metabolic stresses, such as hypoxia, nutrient deprivation and growth factor depletion [24]. It mobilizes intracellular energy to meet cellular demand [4]. Autophagy also functions as a cellular housekeeper in some biological processes, such as the elimination of defective proteins and organelles, the prevention of abnormal protein accumulation, and the removal of intracellular pathogens [24, 25]. Autophagy-lysosome system is critical for maintaining protein quality, preventing intracellular accumulation of mis-folded proteins. In addition, autophagy is shown as a potential genome guardian. Autophagy deficiency in the immortalized epithelial cells limits DNA damage and chromosomal instability [26].

\section{Pathological role of autophagy}

Autophagy is essential for cell survival in many solid tumors. It coordinates the inactivation of apoptosis, and promotes necrosis and tumor progression [27, 28]. Tumor suppressor genes, such as PTEN, TSC1, and TSC2, inhibit mTOR signaling and stimulate autophagy. By contrast, mTOR-activating oncogenes, such as class I PI3K and Akt, inhibit autophagy [29]. Bcl-2 and Bcl-xL are frequently up-regulated in many human tumors. ERlocalized Bcl-2 and Bcl-xL inhibits autophagy by binding to Beclin 1, an autophagy protein [30].

Inadequate or defective autophagy contributes to neuronal cell death in many neurodegenerative disorders, such as Parkinson's (PD), Huntington's, Alzheimer's disease (AD) [31]. Autophagy protects cells from cumulative oxidative damage to proteins and membranes in the aging nervous system [18, 32]. Autophagy also functions as a distinctive death mechanism. Obvious proliferation of autophagic vacuoles and progressive disappearance of organelles was observed in the dying neurons in chick embryo through an ultrastructural study [33].

Autophagy is used as a defense against microbes. Numerous medically important pathogens are degraded by autophagy, such as group A Streptococcus, Mycobacterium 
Fig. 4. Autophagy change in different eye tissues. Schematic of the anatomy of the eye with tables displaying autophagy changes in different tissues leading to ocular diseases.

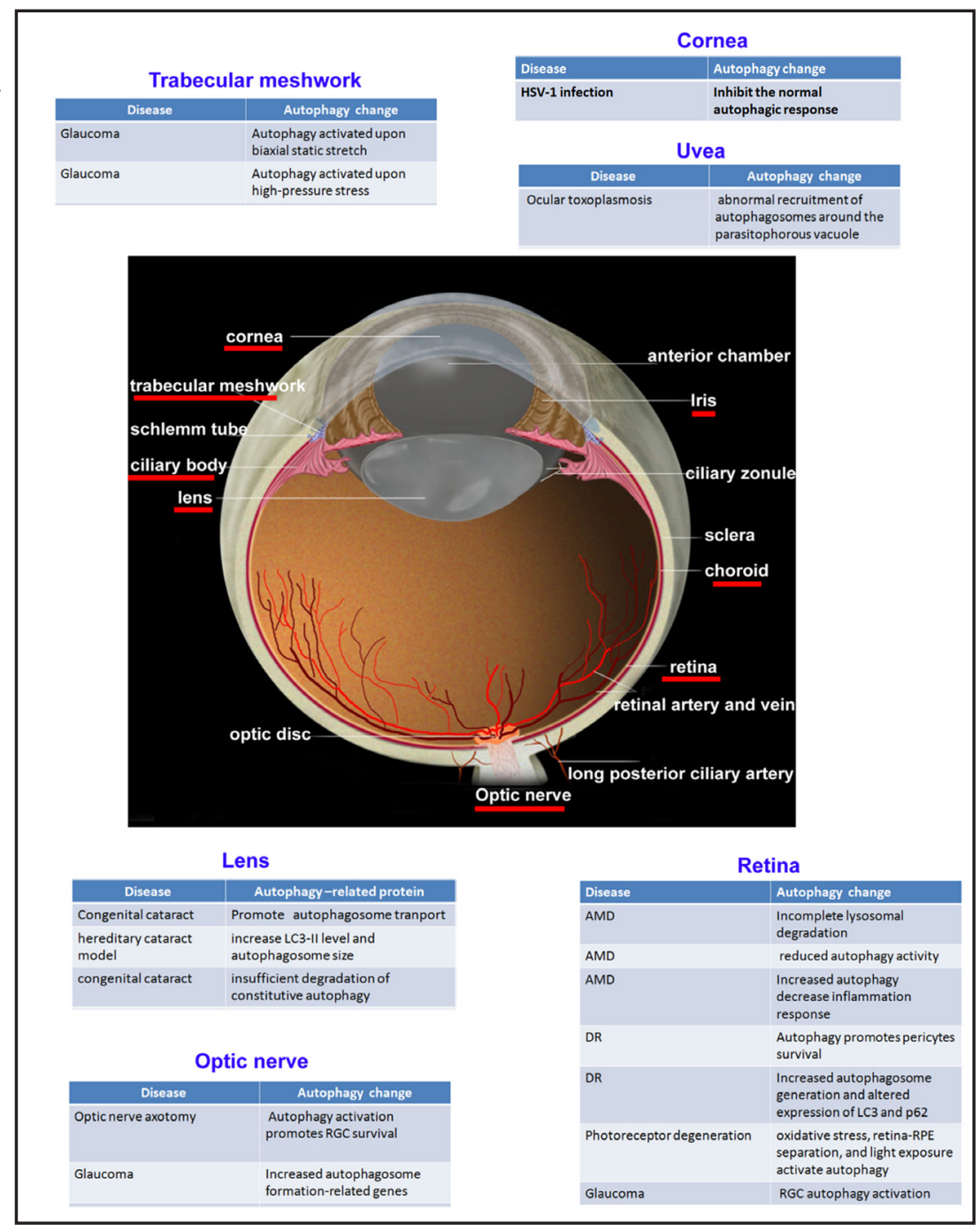

tubercuolosis, Shigella flexneri, Salmonella enterica, Listeria monocytogenes, Francisella tularensis, herpes simplex virus type I (HSV-1), and Toxoplasma gondii [34-36].

Autophagy is shown as a response to cardiac stress such as ischemia or pressure overload [37]. In ischemia reperfusion liver injury, autophagy plays a pro-survival role against nutrient starvation and anoxia stress [38]. Upon hepatitis B or C infection, autophagy is used by some bacteria and viruses to invade host tissues [39, 40]. Autophagy is also an effector of Th1/Th2 polarization. It can fuel MHC II presentation of cytosolic antigens, shape central tolerance, and affect B and T cell homeostasis [41, 42].

\section{Association between autophagy and ocular health or diseases}

Autophagy-related proteins are strongly expressed in the ganglion cell layer, inner nuclear layer, outer nuclear layer, and RPE layer in retina. These cell layers have high metabolic demand and propensity for mitochondrial damage [6]. Under physiological condition, autophagy is a housekeeping process to remove damaged cytoplasmic proteins and cellular organelles [1]. They rely on one or more aspects of autophagy to maintain structure and/or normal physiological function. Autophagy dysregulation is involved in the occurrence of ocular disease (Table 1 and Fig. 4). 


\begin{tabular}{|c|c|c|}
\hline Cellular Physiology & Cell Physiol Biochem 2015;35:1663-1676 & \\
\hline and Biochemistry & $\begin{array}{l}\text { DOI: 10.1159/000373980 } \\
\text { Publisned onine: varch } 18,2015\end{array}$ & $\begin{array}{l}\text { O } 2015 \text { s. Karger AG, Basel } \\
\text { www.karger.com/cpb }\end{array}$ \\
\hline
\end{tabular}

Table 1. Aberrant autophagy process in ocular diseases

\begin{tabular}{|c|c|c|}
\hline Ocular disease & Description & Refs. \\
\hline \multicolumn{3}{|l|}{ T. gondiican } \\
\hline \multicolumn{3}{|l|}{ infection } \\
\hline & $\begin{array}{l}\text { Autophagy dysregualtion due to CD40 } \\
\text { pathway defect }\end{array}$ & $\begin{array}{l}\text { Subauste et al. 1999; Subauste and } \\
\text { Wessendarp, } 2006\end{array}$ \\
\hline \multicolumn{3}{|l|}{ HSV-1 infection } \\
\hline & inhibit normal autophagic response & Leib et al, 2009 \\
\hline \multicolumn{3}{|l|}{ AMD } \\
\hline & $\begin{array}{l}\text { Autophagy increase in the aged retina and } \\
\text { the drusen of AMD donor eyes }\end{array}$ & Wang et al., 2009b \\
\hline & $\begin{array}{l}\text { Increased autophagy during drusen } \\
\text { formation }\end{array}$ & Wang et al., 2009a \\
\hline & Inflammation regulation & Kauppinen et al, 2013 \\
\hline \multirow[t]{5}{*}{ Glaucoma } & Regulation of oxidative stress & Karlsson et al,2013; Wang et al, 2014 \\
\hline & Regulation of TM function & Porter et al., 2013, 2014 \\
\hline & Autophagy is activated after IOP elevation & Piras et al., 2011; Park et al., 2012; \\
\hline & and traumatic injury & Rodríguez-Muela et al., 2012 \\
\hline & $\begin{array}{l}\text { Autophagy activation in the injured neuronal } \\
\text { cells }\end{array}$ & Kim et al., 2008 \\
\hline \multicolumn{3}{|l|}{ Cataract } \\
\hline & $\begin{array}{l}\text { Deletion of autophagy-related } 5 \text { (Atg5) and } \\
\text { Pik3c3 }\end{array}$ & Morishita et al., 2013 \\
\hline & Mutations in FYCO1 & Abouzeid et al., 2012 \\
\hline & aB-crystallin R120G mutation & Wignes et al., 2013 \\
\hline \multicolumn{3}{|l|}{ DR } \\
\hline & $\begin{array}{l}\text { Autophagy induction in pericytes exposed to } \\
\text { HOG-LDL }\end{array}$ & Fu et al, 2012 \\
\hline & High glucose-induced autophagy in RPE & Yao et al., 2014 \\
\hline \multicolumn{3}{|l|}{$\begin{array}{l}\text { Photoreceptor } \\
\text { degeneration }\end{array}$} \\
\hline & $\begin{array}{l}\text { Autophagy is activated in the } \mathrm{rd} / \mathrm{rd} \text { mouse } \\
\text { during light-damage }\end{array}$ & Mellén et al., 2008 \\
\hline & $\begin{array}{l}\text { Autophagy is activated during oxidative } \\
\text { stress }\end{array}$ & $\begin{array}{l}\text { Kunchithapautham and Rohrer, } \\
2007 \mathrm{~b}\end{array}$ \\
\hline & $\begin{array}{l}\text { Autophagy is increased in the retinas of } \\
\text { Abca4-/-Rdh8-/- mice after light exposure }\end{array}$ & Chen et al., 2013 \\
\hline
\end{tabular}

\section{Ocular infectious disease}

Autophagy is critical for the degradation of invading microorganisms. The human cornea is a primary target for T.gondii and HSV-1, which enters endothelial cells through endocytosis. T.gondii survives within the host cells preventing the endosomal-lysosomal compartments from fusing with the vacuoles. It causes ocular toxoplasmosis and/or cerebral toxoplasmosis in adults. Ocular toxoplasmosis is the most common form of posterior uveitis [43]. It occurs in immunocompromised patients or in immunocompetent. CD40 activates macrophages to kill T. gondii through the recruitment of autophagosomes around the parasitophorous vacuole. Defects in CD40 pathway in patients develop cerebral and/or ocular toxoplasmosis, including patients with X-linked Hyper IgM syndrome who lack functional CD154 [44]. CD40-induced autophagic killing of T. gondii may be an important contributor for the control of T. gondii $[45,46]$. HSV-1 is a double-stranded DNA virus in the herpesvirus family. PKRand eIF $2 \alpha$-dependent autophagy mediates the degradation of HSV-1. This virus produces ICP34.5, a neurovirulence factor that inhibits autophagy by the reversal of PKR-mediated eIF $2 \alpha$ phosphorylation and antagonizing Beclin 1 [47, 48]. Corneal HSV-1 infection could subvert cornea's response to infection by inhibiting autophagic response [5]. Collectively, 
these studies reveal that the role of autophagy in controlling microorganism infection is via a rapid induction of the innate immune response.

\section{Age-related macular degeneration (AMD)}

Aging, hypercholesterolaemia, hypertension, obesity, arteriosclerosis, and smoking are risk factors to develop AMD. The pathology of AMD associates with increased oxidative stress, inflammation, and impaired proteasomal or lysosomal function that causes the formation of intra- and extracellular deposits. Autophagy is a cellular housekeeping process that removes damaged organelles and protein aggregates. A breakdown in the recycling capacity of autophagy is strongly linked to AMD pathogenesis [49]. AMD-related stress, such as caloric restriction, hypoxia, oxidative stress, can impair autophagy, increase protein aggregation, and cause inflammasome activation involved in AMD pathogenesis [50,51].

A hallmark of AMD is the detrimental accumulation of lysosomal lipofuscin in RPE cells. The capacity of RPE to modulate diverse pathways of AMD pathogenesis makes it as the fulcrum [52]. Abnormally increased lipofuscin accumulation in RPE cells is observed in early- and late-stage AMD. Lipofuscin exerts phototoxic effects on RPE cells in vitro, resulting in free radical generation and cell apoptosis [53]. Incomplete lysosomal degradation is the underlying mechanism of lipofuscinogenesis [54]. Given the critical role of autophagy in lipofuscin accumulation, it is not surprise that pharmacological manipulation of autophagy may offer an alternative therapeutic target.

In addition to lipofuscin accumulation, reduced autophagy activity has been implicated in RPE dysfunction [55]. Decreased autophagy renders RPE cells susceptible to apoptosis induced by various stress including nutritional depletion and mitochondrial photooxidative damage $[56,57]$. Preservation of autophagic activity could improve RPE function and retard disease progression $[58,59]$. Protein aggregates induce the inflammasome activation in RPE cells. Increased autophagy activates the intracellular cleaning systems, and decreases the generation of inflammasomes, which could prevent inflammation response in AMD [60].

\section{Glaucoma}

Autophagy is an important recycling pathway implicated in neurodegeneration either as a pro-survival or a pro-death mechanism. Progressive RGC death involves novel non-apoptotic programmed cell death (paraptosis) at the early stage of glaucoma, which is accompanied by apoptosis and/or autophagy in the moderate and severe stages [61]. Pharmacological induction of autophagy in vivo increases the number of surviving cells after traumatic injury, suggesting that autophagy has a cytoprotective role in RGCs. Modulation of autophagy may provide a new therapeutic strategy to ameliorate retinal nerve diseases [62]. However, autophagy sometimes plays a detrimental role. The inhibition of autophagy attenuates axonal degeneration and ultrastructural alterations [63]. Elevated IOP could also activate autophagy, and up-regulate the levels of autophagy markers, LC3-II/LC3-I and beclin-1 [63, 64]. Autophagosome formation-related genes, including Atg5, Atg7, Atg12, Beclin-1, and LC3, are significantly activated during neuronal cell injury [65].

Trabecular meshwork (TM) plays important roles in the normal outflow of aqueous. Its abnormality affects the outflow and increases the intraocular pressure, thereby causing glaucoma. Chronic exposure of TM cells to oxidative stress causes the accumulation of nondegradable materials within the lysosomal compartment leading to diminished lysosomal activity. Autophagy in TM cells is also obviously activated upon biaxial static stretch or highpressure stress. This activation allows TM cells to cope with the external stress. Reduced autophagic flux is recognized as a factor of progressive TM dysfunction $[66,67]$.

Optineurin (OPTN) was identified as an autophagy receptor involved in the elimination of cytosolic bacteria [10]. Mutations in OPTN gene are associated with normal-tension 
glaucoma [12]. OPTN E50K is the most common disease causing mutation of optineurin, and overexpression of OPTN E50K mutation in mice lead to a loss of RGCs and other retinal cell types $[11,68]$.

\section{Cataract}

The lens of the eye is composed of fiber cells, which differentiate from epithelial cells and undergo programmed organelle degradation during terminal differentiation. Upon maturation, these differentiating fiber cells lose their organelles to produce the organelle free zone (OFZ) thus contributing to lens transparency. Cataract is the loss of transparency of the lens. The presence of autophagic vesicles was identified in embryonic and adult lens. Autophagy is involved in lens fiber cell maturation and formation of OFZ [69].

Congenital cataracts can be caused by improper clearance of proteins and organelles. FYCO1 is a PI (3) P, Rab7 and LC3 binding protein that mediates microtubule plus enddirected vesicle transport of autophagosomes. Mutation in FYCO1 gene was identified as the cause of autosomal recessive congenital cataract [70]. In hereditary cataract model, $\alpha \mathrm{B}-$ crystallin R120G mutation increases LC3-II level and autophagosome size, and up-regulates p62 level in mouse lens epithelial and fiber cells [71]. Vsp34, a class III phosphatidylinositol 3-kinase, is involved in Atg5-independent autophagy. Vsp34 loss leads to congenital cataract and defective lens development [72]. Connexins form gap junctions, and their short halflife suggests that the degradation and renewal is important for cell-cell contact. CX50 P88S mutant is associated with inherited congenital cataracts. Autophagy can regulate the level of wild-type connexins. The persistence of accumulations of CX50P88S may result from the insufficient degradation of constitutive autophagy [70]. Collectively, these studies provide evidence for the role of autophagy in lens function. Disruption of autophagy causes the loss of lens resistance to stress and/or lens differentiation resulting in cataract formation.

\section{Diabetic retinopathy (DR)}

DR is a serious complication of diabetes mellitus characterized by microvascular dysfunction. Pericytes are essential for retinal capillary structure and function, and the loss is an early feature of DR. Autophagy promotes pericytes survival under mild stress, but lead to their death under extended stress [73]. The outer BRB is comprised of tight junctions between RPE cells. During DR, extra-vascular modified LDL may promote RPE injury through oxidative stress, ER stress, autophagy and apoptosis [74]. High glucose causes a marked increase in autophagosome generation and altered expression of LC3 and p62 in RPE cells [75]. In the scenario of high glucose-induced oxidative stress, autophagy is involved in the removal of damaged proteins, providing a default mechanism to prevent high glucoseinduced injury in RPE cells. Metabolic stress such as growth factor and nutrient deprivation participate in cell death and the accumulation of damaged proteins in diabetic retinas. Autophagy is a major catabolic pathway involved in degrading and recycling damaged organelles and macromolecules to maintain intracellular homeostasis. It contributes to cell energy homeostasis and repair during basal and nutrient stress conditions. Autophagy is altered in diabetic retinopathy in response to the metabolic stress. Thus, autophagy modulation provides a novel avenue for the treatment of diabetes-related diseases.

\section{Photoreceptor degeneration}

The retina provides exquisitely sensitive vision that relies on the integrity of a uniquely vulnerable cell, the photoreceptor (PR). The genetic and mechanistic causes of retinal degeneration due to PR cell death, which occurs in the conditions such as retinitis pigmentosa 


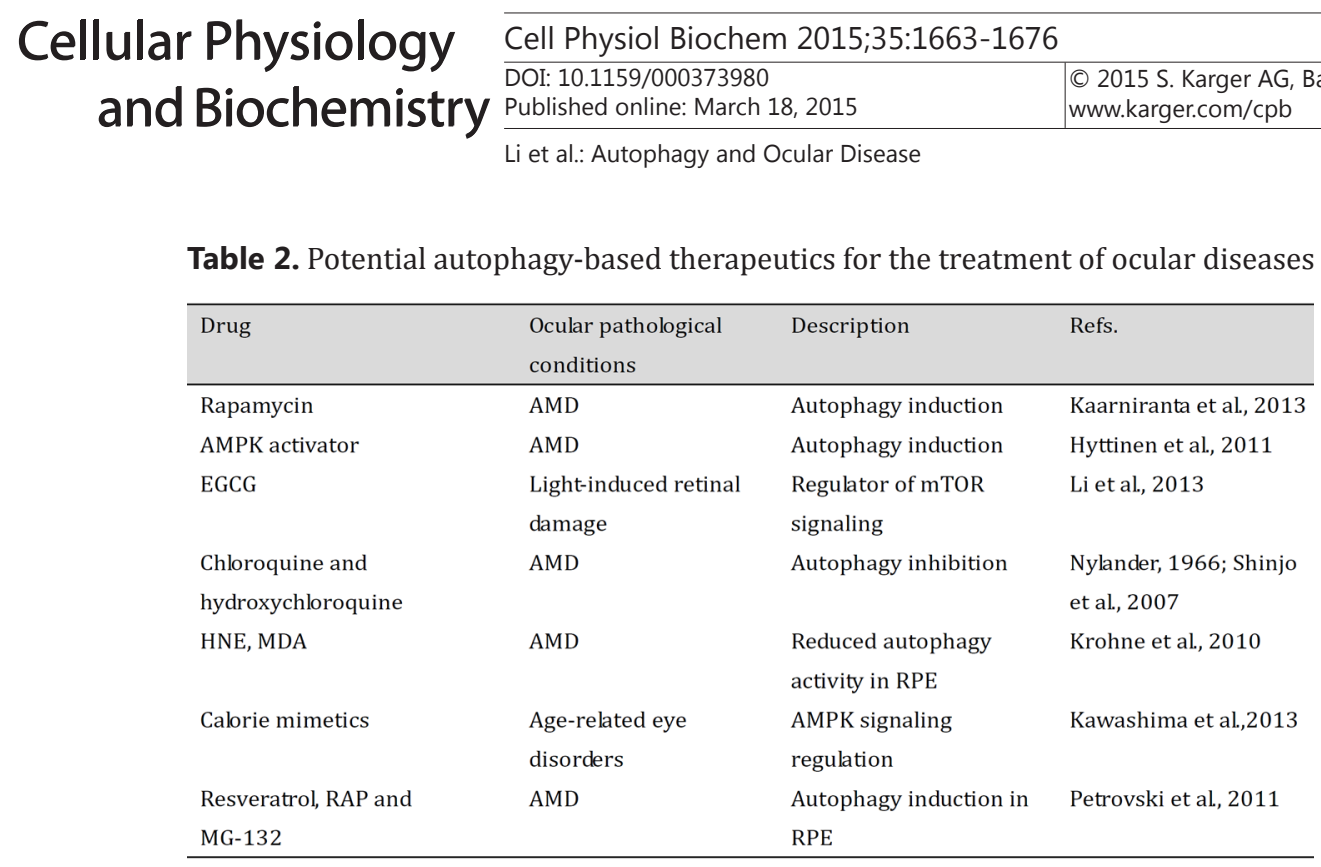

and age-related macular degeneration. Exposure to light damage causes oxidative stress and altered metabolism, which may induce caspase-dependent and caspase-independent rod and cone photoreceptor cell death through the activation of cysteine-proteases, lysosomal proteases and autophagy to overcome damaged protein overload [76-79].

Autophagy and apoptosis occur in parallel in photoreceptor degeneration in the rd/ rd mouse during light-damage [76]. Upon oxidative stress, autophagy is activated to induce photoreceptor cell death both in vivo and in a photoreceptor cell line [77]. Autophagy activation also occurs in the photoreceptors after retina-RPE separation. The activation could prevent Fas-mediated apoptosis [78]. Expression of autophagosome marker and mitochondria-specific autophagy regulator is markedly increased in the retinas of Abca $4 \%$ Rdh8 ${ }^{-/}$mice after light exposure. Autophagy could protect these retinas from light-induced degeneration [79].

\section{Autophagy and ocular disease therapy}

Recently, several studies have revealed that autophagy is a potential target for ocular disease treatment (Table 2). Rapamycin, a regulator of autophagy, is shown as a potential drug for AMD therapy [80, 81]. AMPK is an inhibitor of mTOR signaling, which evokes autophagy induction. AMPK-mTOR axis may also become a target for AMD treatment [82]. Calorie restriction (CR) and its mimetics reverse or slow age-related functional declines in the eye. The involvement of this pathway through which sirtuin 1 (SIRT1) and/or its upstream AMPK acts is a well-known mechanism underlying CR benefits [32]. Chinese medicine acts via a modulation of autophagy $[83,84]$. Epigallocatechin-gallate (EGCG) plays a regulatory role in UVB irradiation-induced autophagy in RPE cells [85].

The induction of lysosomal dysfunction by lipid peroxidation-derived protein modifications, such as 4-hydroxynonenal (HNE) and malondialdehyde (MDA), results in increased lipofuscinogenesis and reduced autophagy activity in RPE, which may contribute to RPE cell dysfunction and degeneration in AMD [86]. Resveratrol at lower concentrations, RAP and MG-132 can provide a pro-survival stimulus to RPE cells through autophagy induction. This property can possibly be used for prolonging RPE lifespan in AMD [87].

Autophagy has the potential to either induce cell death or promote cell survival, suggesting a paradoxical role of autophagy. Chloroquine (CQ) and its derivative hydroxychloroquine (HCQ) have been approved by the FDA due to the effectiveness in vivo and safety in clinical trials. They can suppress autophagy by blocking autophagosome fusion and degradation. Sometimes, both agents bind to the melanin in RPE cells, and this binding may serve to concentrate the agents and prolong their toxic effects. Thus, the incidence of irreversible retinal toxicity may also increase when patients were treated with CQ or HCQ $[88,89]$. 
In the future, it is still required to develop novel regulators that specifically target autophagy machinery [90]. These drugs can be developed for targeting kinases (e.g., class III PI3K), proteases (e.g., Atg4B and C), and E1 or E2-like enzymes (Atg7 and Atg10) [91]. In addition, the existing less-specific autophagy activators (rapamycin analogues) and inhibitors (chloroquine and omeprazole) that are reasonably well-tolerated may enlighten the efficacy of autophagy regulation in the treatment of ocular diseases [92].

\section{Concluding remarks}

In this review, we summarized current knowledge about the role of autophagy in ophthalmic research. We know that functional autophagy is critical for retinal cell survival, development, and homeostasis [2]. Autophagy dysregulation could lead to the occurrence of several ocular diseases. Under most circumstances, autophagy functions as homeostatic mechanism for intracellular recycling and metabolic regulation [3]. Autophagy is critical for the removal of damaged proteins and organelles. Continuous autophagy activation may cause non-apoptotic programmed cell death. Thus, it is required to control the balance between too little and too much autophagy [4].

Autophagy is a double-edged sword in health and disease. Cells exposed to growth factor deprivation or glucose and oxygen shortage can lose the majority of their mass through autophagy. By contrast, it fully recovers when placed in optimal culture conditions $[28,93]$, implying that autophagy-mediated cell death is not a simple matter of crossing a quantitative threshold of self-digestion. Thus, it is critical for understanding how autophagy executes or protects against external stress before developing effective therapeutic or preventive interventions for ocular diseases. In addition, it is still required to determine whether altered autophagy is causative or secondary to the pathological processes of ocular diseases.

As a conserved cellular pathway, the process of autophagy should be tightly regulated. Signaling pathways, including mTOR, AMPK, oxidative stress, and ER stress signaling, are involved in autophagy regulation. Whether these signaling pathways crosstalk between each other or whether there is other signaling pathway involved in autopahgy regulation is still unknown. Thus, further understanding autophagy regulation may allow us to develop therapeutic strategy to enhance chemotherapy effect and improve clinical outcomes during ocular disease treatment.

\section{Funding}

This work was generously supported by grants from the National Natural Science Foundation of China (Grant No 81300241 and 81470594 B.Y. and Grant No. 81371055 to Q.J.), grants from the National clinical key construction project [Grant No. (2012) 649 to Q.J.], and grants from the Medical Science and Technology Development Project Fund of Nanjing (Grant No. ZKX 12047 to Q.J., Grant No. YKK12207 to G. F.-C., Grant No. YKK12208 to J.Y., and Grant No. YKK13227 to B.Y.)

\section{Disclosure Statement}

None declared.

\section{Reference}

1 Shintani T, Klionsky DJ: Autophagy in health and disease: a double-edged sword. Science 2004;306:990995.

2 Mizushima N, Levine B, Cuervo AM, Klionsky DJ: Autophagy fights disease through cellular self-digestion. Nature 2008;451:1069-1075. 
3 Kundu M, Thompson CB: Autophagy: Basic principles and relevance to disease. Annu Rev Pathol 2008;3:427-455.

4 Levine B, Kroemer G: Autophagy in the pathogenesis of disease. Cell 2008;132:27-42.

5 Leib DA, Alexander DE, Cox D, Yin J, Ferguson TA: Interaction of ICP34.5 with beclin 1 modulates herpes simplex virus type 1 pathogenesis through control of CD4+ T-cell responses. J Virol 2009;83:12164-12171.

6 Jarrett SG, Lewin AS, Boulton ME: The importance of mitochondria in age-related and inherited eye disorders. Ophthalmic Res 2010;44:179-190.

7 Viiri J, Amadio M, Marchesi N, , Hyttinen JM, Kivinen N, Sironen R, Rilla K, Akhtar S, Provenzani A, D’Agostino VG, Govoni S, Pascale A, Agostini H, Petrovski G, Salminen A, Kaarniranta K: Autophagy activation clears ELAVL1/HuR-mediated accumulation of SQSTM1/p62 during proteasomal inhibition in human retinal pigment epithelial cells. PloS ONE 2013;8:e69563.

-8 Sahu R, Kaushik S, Clement CC, Cannizzo ES, Scharf B, Follenzi A, Potolicchio I, Nieves E, Cuervo AM, Santambrogio L: Microautophagy of cytosolic proteins by late endosomes. Dev Cell 2011;20:131-139.

-9 Belaid A, Ndiaye PD, Klionsky DJ, Hofman P, Mograbi B: Scheduled signal termination by macroautophagy. Autophagy 2013;9:1629-1630.

10 Wild P, Farhan H, McEwan DG, Wagner S, Rogov VV, Brady NR, Richter B, Korac J, Waidmann O, Choudhary C, Dötsch V, Bumann D, Dikic I: Phosphorylation of the autophagy receptor optineurin restricts salmonella growth. Science 2011;333:228-233.

11 Chi ZL, Akahori M, Obazawa M, Minami M, Noda T, Nakaya N, Tomarev S, Kawase K, Yamamoto T, Noda S, Sasaoka M, Shimazaki A, Takada Y, Iwata T: Overexpression of optineurin E50K disrupts Rab8 interaction and leads to a progressive retinal degeneration in mice. Hum Mol Genet 2010 19(13):2606-2615.

-12 Rezaie T, Child A, Hitchings R, Brice G, Miller L, Coca-Prados M, Héon E, Krupin T, Ritch R, Kreutzer D, Crick RP, Sarfarazi M: Adult-onset primary open-angle glaucoma caused by mutations in optineurin. Science 2002;295:1077-1079.

13 Rubinsztein DC, Shpilka T, Elazar Z: Mechanisms of autophagosome biogenesis. Curr Biol 2012;22:R29-R34.

14 Mizushima N: The role of the ATG1/ULK1 complex in autophagy regulation. Curr Opin Cell Biol 2010;22:132-139.

15 Zoncu R, Efeyan A, Sabatini DM: mTOR: from growth signal integration to cancer, diabetes and ageing. Nat Rev Mol Cell Biol 2011;12:21-35.

16 Kim J, Kundu M, Viollet B, Guan KL: AMPK and mTOR regulate autophagy through direct phosphorylation of ULK1. Nat Cell Biol 2011;13:132-141.

17 Mihaylova MM, Shaw RJ: The AMPK signalling pathway coordinates cell growth, autophagy and metabolism. Nat Cell Biol 2011;13:1016-1023.

18 Mitter SK, Song C, Qi X, Mao H, Rao H, Akin D, Lewin A, Grant M, Dunn W Jr, Ding J, Bowes Rickman C, Boulton M:Dysregulated autophagy in the RPE is associated with increased susceptibility to oxidative stress and AMD.Autophagy 2014;10:1989-2005.

19 Baird L, Dinkova-Kostova AT: The cytoprotective role of the KEAP1-NRF2 pathway. Arch Toxicol 2011;85:241-272.

20 Ichimura Y, Waguri S, Sou YS, Kageyama S, Hasegawa J, Ishimura R, Saito T, Yang Y, Kouno T, Fukutomi T, Hoshii T, Hirao A, Takagi K, Mizushima T, Motohashi H, Lee MS, Yoshimori T, Tanaka K, Yamamoto M, Komatsu M: Phosphorylation of p62 activates the KEAP1-NRF2 pathway during selective autophagy. Mol Cell 2013;51:618-631.

21 Inami Y, Waguri S, Sakamoto A, Kouno T, Nakada K, Hino O, Watanabe S, Ando J, Iwadate M, Yamamoto M, Lee MS, Tanaka K, Komatsu M: Persistent activation of nrf2 through p62 in hepatocellular carcinoma cells. J Cell Biol 2011;193:275-284.

-22 Lau A, Wang XJ, Zhao F, Villeneuve NF, Wu T, Jiang T, Sun Z, White E, Zhang DD: A noncanonical mechanism of NRF2 activation by autophagy deficiency: Direct interaction between KEAP1 and p62. Mol Cell Biol 2010;30:3275-3285.

$23 \mathrm{Xu}$ Y, Xia X, Pan H: Active autophagy in the tumor microenvironment: a novel mechanism for cancer metastasis. Oncol Lett 2013;5:411-416.

24 Mizushima N, Klionsky DJ: Protein turnover via autophagy: Implications for metabolism. Annu Rev Nutr 2007;27:19-40. 
25 Pankiv S, Clausen TH, Lamark T, Brech A, Bruun JA, Outzen H, Øvervatn A, Bjørkøy G, Johansen T: P62/ SQSTM1 binds directly to ATG8/LC3 to facilitate degradation of ubiquitinated protein aggregates by autophagy. J Biol Chem 2007;282:24131-24145.

26 Mathew R, Karantza-Wadsworth V, White E: Role of autophagy in cancer. Nat Rev Cancer 2007;7:961-967.

27 Karantza-Wadsworth V, White E: Role of autophagy in breast cancer. Autophagy 2007;3:610-613.

28 Degenhardt K, Mathew R, Beaudoin B, Bray K, Anderson D, Chen G, Mukherjee C, Shi Y, Gélinas C, Fan Y, Nelson DA, Jin S, White E: Autophagy promotes tumor cell survival and restricts necrosis, inflammation, and tumorigenesis. Cancer Cell 2006;10:51-64.

29 Liang J, Shao SH, Xu ZX, Hennessy B, Ding Z, Larrea M, Kondo S, Dumont DJ, Gutterman JU, Walker CL, Slingerland JM, Mills GB: The energy sensing LKB1-AMPK pathway regulates p27KIP1 phosphorylation mediating the decision to enter autophagy or apoptosis. Nat Cell Biol 2007;9:218-224.

-30 Maiuri MC, Le Toumelin G, Criollo A, Rain JC, Gautier F, Juin P, Tasdemir E, Pierron G, Troulinaki K, Tavernarakis N, Hickman JA, Geneste O, Kroemer G : Functional and physical interaction between Bcl-xl and a BH3-like domain in beclin-1. EMBO J 2007;26:2527-2539.

-31 Nixon RA: The role of autophagy in neurodegenerative disease. Nat Med 2013;19:983-997.

- 32 Kawashima M, Ozawa Y, Shinmura K, Inaba T, Nakamura S, Kawakita T, Watanabe M, Tsubota K: Calorie restriction (CR) and CR mimetics for the prevention and treatment of age-related eye disorders. Exp Gerontol 2013;48:1096-1100.

33 Hornung J, Koppel H, Clarke P: Endocytosis and autophagy in dying neurons: an ultrastructural study in chick embryos. J Comp Neurol 1989;283:425-437.

-34 Portillo J-AC, Okenka G, Reed E, Subauste A, Van Grol J, Gentil K, Komatsu M, Tanaka K, Landreth G, Levine B, Subauste CS: The CD40-autophagy pathway is needed for host protection despite IFN- $\gamma$-dependent immunity and CD40 induces autophagy via control of p21 levels. PloS One 2010;5:e14472.

-35 Leib DA, Alexander DE, Cox D, Yin J, Ferguson TA: Interaction of ICP34. 5 with beclin 1 modulates herpes simplex virus type 1 pathogenesis through control of CD4+ T-cell responses. J Virol 2009;83:12164-12171.

-36 Levine B, Deretic V: Unveiling the roles of autophagy in innate and adaptive immunity. Nat Rev Immunol 2007;7:767-777.

- 37 Nishida K, Kyoi S, Yamaguchi O, Sadoshima J, Otsu K: The role of autophagy in the heart. Cell Death Differ 2008;16:31-38.

38 Yin XM, Ding WX, Gao W: Autophagy in the liver. Hepatology 2008;47:1773-1785.

39 Shrivastava S, Raychoudhuri A, Steele R, Ray R, Ray RB: Knockdown of autophagy enhances the innate immune response in hepatitis C virus-infected hepatocytes. Hepatology 2011;53:406-414.

40 Tang H, Da L, Mao Y, Li Y, Li D, Xu Z, Li F, Wang Y, Tiollais P, Li T: Hepatitis b virus X protein sensitizes cells to starvation-induced autophagy via up-regulation of beclin 1 expression. Hepatology 2009;49:60-71.

-41 41 .Harris J, Master SS, De Haro SA, Delgado M, Roberts EA, Hope JC, Keane J, Deretic V: Th1-Th2 polarisation and autophagy in the control of intracellular mycobacteria by macrophages. Vet Immunol Immunopathol 2009;128:37-43.

42 Delgado M, Singh S, De Haro S, Master S, Ponpuak M, Dinkins C, Ornatowski W, Vergne I, Deretic V: Autophagy and pattern recognition receptors in innate immunity. Immunol Rev 2009;227:189-202.

43 McCannel CA, Holland GN, Helm CJ, , Cornell PJ, Winston JV, Rimmer TG: Causes of uveitis in the general practice of ophthalmology. Am J Ophthalmol 1996;121:35-46.

44 Subauste CS, Wessendarp M, Sorensen RU, Leiva L: CD40-CD40 ligand interaction is central to cellmediated immunity against Toxoplasma gondii: patients with hyper IgM syndrome have a defective type-1 immune response which can be restored by soluble CD40L trimer. J Immunol 1999;162:6690-6700.

45 Subauste CS, Wessendarp M: CD40 restrains the in vivo growth of Toxoplasma gondii independently of gamma interferon. Infect Immun 2006;74:1573-1579.

46 Subauste CS, Andrade RM, Wessendarp M: CD40-TRAF6 and autophagy-dependent antimicrobial activity in macrophages. Autophagy 2007;3:245-248.

47 Talloczy Z, Virgin HW, Levine B: PKR-dependent autophagic degradation of herpes simplex virus type 1. Autophagy 2005; 2:24-29.

-48 Orvedahl A, Alexander D, Talloczy Z, Sun Q, Wei Y, Zhang W, Burns D, Leib DA, Levine B: HSV-1 ICP34.5 confers neurovirulence by targeting the Beclin 1 autophagy protein. Cell Host Microbe 2007; 1:23-35.

-49 Wang AL, Lukas TJ, Yuan M, Du N, Tso MO, Neufeld AH: Autophagy, exosomes and drusen formation in agerelated macular degeneration. Autophagy 2009;5:563-564. 
50 Arjamaa 0, Nikinmaa M, Salminen A, Kaarniranta K: Regulatory role of HIF-1 $\alpha$ in the pathogenesis of agerelated macular degeneration (AMD). Ageing Res Rev 2009;8:349-358.

51 Kaarniranta K, Salminen A: Age-related macular degeneration: Activation of innate immunity system via pattern recognition receptors. J Mol Med (Berl) 2009;87:117-123.

-52 Holz FG, Schütt F, Kopitz J, Eldred GE, Kruse FE, Völcker HE, Cantz M: Inhibition of lysosomal degradative functions in RPE cells by a retinoid component of lipofuscin. Invest Ophthalmol Vis Sci 1999;40:737-743.

53 Schütt F, Davies S, Kopitz J, Holz FG, Boulton ME: Photodamage to human RPE cells by A2-E, a retinoid component of lipofuscin. Invest Ophthalmol Vis Sci 2000;41:2303-2308.

-54 Sparrow JR, Boulton M: RPE lipofuscin and its role in retinal pathobiology. Exp Eye Res 2005;80:595-606.

-55 Kaarniranta K, Salminen A, Eskelinen EL, Kopitz J: Heat shock proteins as gatekeepers of proteolytic pathways-implications for age-related macular degeneration (AMD). Ageing Res Rev 2009;8:128-139.

56 Boya P, González-Polo RA, Casares N, Perfettini JL, Dessen P, Larochette N, Métivier D, Meley D, Souquere S, Yoshimori T, Pierron G, Codogno P, Kroemer G: Inhibition of macroautophagy triggers apoptosis. Mol Cell Biol 2005; 25:1025-1040.

-57 Wang AL, Lukas TJ, Yuan M, Du N, Tso MO, Neufeld AH: Autophagy and exosomes in the aged retinal pigment epithelium: Possible relevance to drusen formation and age-related macular degeneration. PLoS One 2009;4:e4160.

-58 Ryhänen T, Hyttinen JM, Kopitz J, Rilla K, Kuusisto E, Mannermaa E, Viiri J, Holmberg CI, Immonen I, Meri S, Parkkinen J, Eskelinen EL, Uusitalo H, Salminen A, Kaarniranta K: Crosstalk between Hsp70 molecular chaperone, lysosomes and proteasomes in autophagy-mediated proteolysis in human retinal pigment epithelial cells. J Cell Mol Med 2009;13:3616-3631.

-59 Salminen A, Kaarniranta K: Regulation of the aging process by autophagy. Trends Mol Med 2009;15:217224.

-60 Kauppinen A, Piippo N, Hytti M, Kinnunen K, Salminen A, Kaarniranta K: Prevention of autophagy activates inflammasome signaling in ARPE-19 cells treated with a proteasome inhibitor. Acta ophthalmol 2013;91:S252.

-61 Wang Y, Xu K, Zhang H, Zhao J, Zhu X, Wang Y, Wu R: Retinal ganglion cell death is triggered by paraptosis via reactive oxygen species production: a brief literature review presenting a novel hypothesis in glaucoma pathology. Mol Med Rep 2014;10:1179-1183.

62 Rodríguez-Muela N, Germain F, Mariño G, Fitze PS, Boya P: Autophagy promotes survival of retinal ganglion cells after optic nerve axotomy in mice. Cell Death Differ 2012;19:162-169.

-63 Knöferle J, Koch JC, Ostendorf T, Michel U, Planchamp V, Vutova P, Tönges L, Stadelmann C, Brück W, Bähr M, Lingor P: Mechanisms of acute axonal degeneration in the optic nerve in vivo. Proc Natl Acad Sci U S A 2010;30:107:6064-6069.

64 Park HL, Kim J, Park C: Activation of autophagy induces retinal ganglion cell death in a chronic hypertensive glaucoma model. Cell Death Dis 2012;3:e290.

65 Kim SH, Munemasa Y, Kwong JM, Ahn JH, Mareninov S, Gordon LK, Caprioli J, Piri N: Activation of autophagy in retinal ganglion cells. J Neurosci Res 2008;86:2943-2951.

66 Porter K, Nallathambi J, Lin Y, Liton PB: Lysosomal basification and decreased autophagic flux in oxidatively stressed trabecular meshwork cells: Implications for glaucoma pathogenesis. Autophagy 2013;9:581-594.

-67 Porter KM, Jeyabalan N, Liton PB: mTOR-independent induction of autophagy in trabecular meshwork cells subjected to biaxial stretch. Biochim Biophys Acta 2014;1843:1054-1062.

68 Chalasani ML, Radha V, Gupta V, Agarwal N, Balasubramanian D, Swarup G: A glaucoma-associated mutant of optineurin selectively induces death of retinal ganglion cells which is inhibited by antioxidants. Invest Ophthalmol Vis Sci 2007;48:1607-1614.

-69 Chen J, Ma Z, Jiao X, Fariss R, Kantorow WL, Kantorow M, Pras E, Frydman M, Pras E, Riazuddin S: Mutations in FYCO1 cause autosomal-recessive congenital cataracts. Am J Hum Genet 2011;88:827-838.

70 Abouzeid H, Helmy G, El sada M, Sherif M,Yacoub M,Boisset G, Favez T,Schorderet D: FYCO1 mutation hotspot in congenital cataract. Acta Ophthalmol 2012;90.

71 Wignes JA, Goldman JW, Weihl CC, Bartley MG, Andley UP: p62 expression and autophagy in $\alpha$ b-crystallin R120G mutant knock-in mouse model of hereditary cataract. Exp Eye Res 2013;115:263-273.

72 Morishita H, Eguchi S, Kimura H, Sasaki J, Sakamaki Y, Robinson ML, Sasaki T, Mizushima N: Deletion of autophagy-related 5 (ATG5) and pik3c3 genes in the lens causes cataract independent of programmed organelle degradation. J Biol Chem 2013;288:11436-11447. 
73 Fu D, Wu M, Zhang J, Du M, Yang S, Hammad S, Wilson K, Chen J, Lyons T: Mechanisms of modified IDLinduced pericyte loss and retinal injury in diabetic retinopathy. Diabetologia 2012;55:3128-3140.

74 Du M, Wu M, Fu D, Yang S, Chen J, Wilson K, Lyons T: Effects of modified ldl and hdl on retinal pigment epithelial cells: a role in diabetic retinopathy? Diabetologia 2013;56:2318-2328.

75 Yao J, Tao ZF, Li CP, Li XM, Cao GF, Jiang Q, Yan B: Regulation of autophagy by high glucose in human retinal pigment epithelium. Cell Physiol Biochem 2014;33:107-116.

76 Mellén M, De La Rosa E, Boya P: The autophagic machinery is necessary for removal of cell corpses from the developing retinal neuroepithelium. Cell Death Differ 2008;15:1279-1290.

77 Kunchithapautham K, Rohrer B: Apoptosis and autophagy in photoreceptors exposed to oxidative stress. Autophagy 2007;3:433-441.

78 Besirli CG, Chinskey ND, Zheng QD, Zacks DN: Autophagy activation in the injured photoreceptor inhibits fas-mediated apoptosis. Invest Ophthalmol Vis Sci 2011;52:4193-4199.

79 Chen Y, Sawada O, Kohno H, Le YZ, Subauste C, Maeda T, Maeda A: Autophagy protects the retina from lightinduced degeneration. J Biol Chem 2013;288:7506-7518.

80 Kaarniranta K, Kauppinen A, Blasiak J, Salminen A: Autophagy regulating kinases as potential therapeutic targets for age-related macular degeneration. Future Med Chem 2012;4:2153-2161.

-81 Kaarniranta K, Sinha D, Blasiak J, Kauppinen A, Veréb Z, Salminen A, Boulton ME, Petrovski G: Autophagy and heterophagy dysregulation leads to retinal pigment epithelium dysfunction and development of agerelated macular degeneration. Autophagy 2013;9:973-984.

82 Hyttinen JM, Petrovski G, Salminen A, Kaarniranta K: $5 `$-adenosine monophosphate-activated protein kinase-mammalian target of rapamycin axis as therapeutic target for age-related macular degeneration. Rejuvenation Res 2011;14:651-660.

83 Zhou J, Farah BL, Sinha RA, Wu Y, Singh BK, Bay B-H, Yang CS, Yen PM: Epigallocatechin-3-gallate (EGCG), a green tea polyphenol, stimulates hepatic autophagy and lipid clearance. PLoS ONE 2014;9:e87161.

84 Li W, Zhu S, Li J, Assa A, Jundoria A, Xu J, Fan S, Eissa NT, Tracey KJ, Sama AE: EGCG stimulates autophagy and reduces cytoplasmic HMGB1 levels in endotoxin-stimulated macrophages. Biochem Pharmacol 2011;81:1152-1163.

85 Li CP, Yao J, Tao ZF, Li XM, Jiang Q Yan B: Epigallocatechin-gallate (EGCG) regulates autophagy in human retinal pigment epithelial cells: A potential role for reducing uvb light-induced retinal damage. Biochem Biophys Res Commun 2013;438:739-745.

86 Krohne TU, Stratmann NK, Kopitz J, Holz FG: Effects of lipid peroxidation products on lipofuscinogenesis and autophagy in human retinal pigment epithelial cells. Exp Eye Res 2010;90:465-471.

87 Petrovski G, Berenyi E, Albert R, Moe M, Fesus L, Berta A: Resveratrol, rapamycin and MG-132 as inducers of autophagy in ARPE-19 cells. Acta Ophthalmologica 2011;89:S248.

88 Nylander U: Ocular damage in chloroquine therapy. Acta Ophthalmol 1966;44:335-348.

89 Shinjo SK, Júnior OOM, Tizziani VA, Morita C, Kochen JA, Takahashi WY, Laurindo IM: Chloroquineinduced bull's eye maculopathy in rheumatoid arthritis: Related to disease duration? Clin Rheumatol 2007;26:1248-1253.

90 Meijer AJ, Codogno P: Regulation and role of autophagy in mammalian cells. Int J Biochem Cell Biol 2004;36:2445-2462.

-91 Ravikumar B, Sarkar S, Davies JE, Futter M, Garcia-Arencibia M, Green-Thompson ZW, Jimenez-Sanchez M, Korolchuk VI, Lichtenberg M, Luo S, Massey DC, Menzies FM, Moreau K, Narayanan U, Renna M, Siddiqi FH, Underwood BR, Winslow AR, Rubinsztein DC: Regulation of mammalian autophagy in physiology and pathophysiology. Physiol Rev 2010;90:1383-1435.

92 Liu B, Cheng Y, Liu Q Bao JK, Yang JM: Autophagic pathways as new targets for cancer drug development. Acta Pharmacol Sin 2010;31:1154-1164.

93 Lum JJ, Bauer DE, Kong M, Harris MH, Li C, Lindsten T, Thompson CB: Growth factor regulation of autophagy and cell survival in the absence of apoptosis. Cell 2005;120:237-248. 